\title{
Evaluation of two school smoking education programmes under normal classroom conditions
}

\author{
Don Nutbeam, Petra Macaskill, Christopher Smith, Judy M Simpson, John Catford
}

Abstract

Objectives-To assess the effectiveness of two school based smoking education projects in delaying onset of smoking behaviour and in improving health knowledge, beliefs, and values.

Design-Cluster randomised controlled trial of two projects taught under normal classroom conditions. Schools were allocated to one of four groups to receive the family smoking education project (FSE); the smoking and me project (SAM); both projects in sequence (FSE/SAM); or no intervention at all.

Setting-39 schools in Wales and England matched for size and catchment profile.

Subjects-All first year pupils in the schools were included and were assessed on three occasions (4538 before teaching (1988), 3930 immediately after teaching (1989), 3786 at one year follow up (1990)).

Main outcome measures-Self reported smoking behaviour (backed by saliva sample) and change in relevant health knowledge, beliefs, and values.

Results-No consistent significant differences in smoking behaviour, health knowledge, beliefs, or values were found between the four groups. For never smokers at baseline the rate of remaining never smokers in 1990 was $74 \%(594 / 804)$ in the control group, 65\% (455/704) in the FSE group, 70\% $(440 / 625)$ in the SAM group, and 69\% (549/791) in the FSE/SAM group $\left(\chi_{a d j}^{2}=6 \cdot 1, d f=3, p=0 \cdot 1\right)$. Knowledge about effects of smoking rose in all groups from a mean score of 5.4 in 1988 to 6.4 in 1989 and 6.5 in 1990.

Conclusions-More comprehensive interventions than school health education alone will be needed to reduce teenage smoking. Other measures including further restrictions on access to cigarettes and on the promotion of tobacco products need to be considered. Further research will be needed to develop effective school based health education projects, which should be formally field tested under normal conditions before widespread dissemination.

Department of Public Sydney, Sydney, New South Wales 2006, Australia

Don Nutbeam, professor of public health

Petra Macaskill, professional officer in biostatistics Judy M Simpson, senior lecturer in biostatistics

\section{Health Promotion}

Authority for Wales, Cardiff CF2 1EB

Christopher Smith, chief of research and policy development

John Catford, executive director

Correspondence to: Professor Nutbeam attention has been given to assessing their effectiveness. An international review of evaluated programmes published in 1978 concluded that most of these early programmes failed to influence smoking behaviour (although several had achieved educational objectives such as improving knowledge and understanding of the relation between smoking and disease). ${ }^{10}$ The failure to reduce smoking was partly ascribed to a naive understanding of the relation between knowledge and changes in behaviour as well as to the use of inappropriate teaching techniques.

During the late 1970s and early 1980s several innovative and more sophisticated approaches to smoking education in schools were developed and evaluated. ${ }^{11-14}$ These drew heavily on psychosocial theories to explain adolescent health behaviour (particularly social learning theory) and were designed to help young people to develop the personal skills needed to resist social pressures to smoke. These programmes also used modern approaches to teaching and learning - for example using classroom videos and pupil led classroom discussion and seeking to include the family more directly in smoking education.

Two programmes that attracted particular attention were the Minnesota smoking prevention programme, which was developed in the United States in the early $1980 \mathrm{~s}$, and the family smoking education project, which was developed in Norway as part of a comprehensive five year research programme examining smoking among Norwegian schoolchildren. Both projects reported success in delaying onset of smoking among adolescents and in achieving lower levels of smoking uptake. ${ }^{1214}$ In both cases only short term follow up studies have been reported.

These projects were adapted by the Health Education Council (now the Health Education Authority) for use in Britain. For the family smoking education project this adaptation was straightforward and the basic educational principles and content are similar in the British and Norwegian versions. ${ }^{15}$ The project was intended for use with first year secondary school pupils (aged 11-12 years) and involves an average of three hours of teaching over a series of classroom lessons. The lessons are reinforced by a booklet for the pupils and a separate leaflet for the parents which encourages them to discuss smoking with their children. The project focuses on the immediate health impact of smoking on the pupils and encourages parents to reinforce the messages from school and to show disapproval of smoking. The project has been used widely throughout England, Wales, and Northern Ireland since becoming available in 1986. The development and dissemination of the family smoking education project were examined as part of the development of the English language version, but the project's effect on smoking behaviour has not been thoroughly evaluated. ${ }^{10}$

The Minnesota smoking prevention programme required teaching methods which were less familiar to many British teachers at that time. The project went through lengthy development and field testing before the project teachers' guide and teacher training manual were published. The British version of the programme 
(smoking and me) became available in 1987 and was based on a series of five lessons intended for secondary school pupils aged 12-13. ${ }^{17}$ All schools using the project are strongly encouraged to have at least one staff member attend a day long training course to provide background information and to familiarise teachers with the technique of pupil led discussion groups, which are an important feature of the project. There are no pupil project materials and the lessons focus on the social consequences of smoking and on peer, family, and media influences on smoking. Emphasis is also placed on practising skills for managing social situations in which smoking occurs. Both teachers' and pupils' views of the project were examined in its development phase, but the project's effect on pupil smoking behaviour has not been formally assessed. ${ }^{18}$

We conducted a two year study to assess the effectiveness of the family smoking education and smoking and me projects in influencing smoking behaviour. The projects were examined individually and in combination.

\section{Subjects and methods}

We studied pupils from 39 mixed sex state comprehensive schools in four different education authorities in Wales and England. The schools were not a strict random sample since in two of the areas schools were approached because of their past commitment to health education. In the other two authorities the schools were selected randomly from school lists. The schools were matched by size and catchment area and assigned to one of four groups: no planned intervention (control group; 10 schools), family smoking education project only (FSE group; 10 schools), smoking and me project only (SAM group; nine schools), and both projects in sequence (FSE/SAM group; 10 schools). This method of assignment was intended to ensure that the groups contained schools from each of the participating authorities and were not widely different in terms of the social background of pupils, school size, and environment. All pupils in the first year of the schools were included, ensuring that each group was sufficiently large to detect differences between the intervention and control groups of the same size as had been achieved in the original evaluation of the two interventions. ${ }^{1214}$

The basic study instrument was a self administered questionnaire which was completed on three occasions by all pupils. The first questionnaire was completed in February to March 1988 before the smoking education projects were started. Schools allocated to teach the FSE project taught it during the three months immediately after administration of the questionnaire. Those schools allocated to use the SAM project taught it in the early part of the second school year November 1988 to February 1989) and the first follow up study was conducted in March 1989. The second follow up study was completed in March 1990.

The part of the questionnaire assessing smoking behaviour was largely derived from the Office of Population Censuses and Surveys studies and previous studies of adolescent health behaviour conducted in Wales. ${ }^{719}$ Questions designed to evaluate the educational objectives of the projects were derived from other studies assessing self esteem and locus of control. ${ }^{2021} \mathrm{~A}$ separate question specifically addressing the knowledge elements of the projects was also developed. Teachers supervised completion of the questionnaire according to a well defined protocol. All teachers were personally briefed on this procedure, which is designed to minimise underreporting of smoking behaviour. ${ }^{22}$

Saliva samples were also taken from all pupils in each of the three surveys. The pupils were told before completing the questionnaire that they would be required to provide a saliva sample to check the accuracy of their reported behaviour. This method, known as the "bogus pipeline" technique, is reported to improve the accuracy of self reported current smoking. ${ }^{23}$

The projects were tested under real life conditions by classroom teachers operating within the normal constraints of teaching. Although clear guidelines were set down for teachers on the minimum time commitment and core content of each of the projects, the organisation and management of the projects were at the discretion of the teacher. All teachers who taught the family smoking education project were briefed on the basic components of the project and provided with basic guideline notes, which included a teacher's record of the lessons. This record provided a short report on the timing, method, and content of each lesson, together with an overall assessment of the usefulness of materials. The results from this part of the study have been published..$^{24}$

The teachers who were selected to teach the smoking and me project were required to attend a one day training seminar which familiarised them with the project guide and the group leader approach to teaching. One course was run in each of the four areas to a consistent format. Teachers were also required to complete a record sheet providing basic details on each lesson taught together with an overall assessment of the project. The results from this part of the project have also been published. ${ }^{25}$ These two studies of the teaching of the project have been important in ensuring that the core elements of both projects were covered and have provided important additional information on the practicalities of teaching the projects and variability in actual classroom use.

DATA ANALYSIS

Because schools rather than individual pupils were assigned to intervention groups responses of pupils within a school (cluster) tend to be correlated and hence the effective sample size is less than the number of students surveyed. The statistical analyses take into account this correlation and the nesting of schools within intervention groups, thus avoiding underestimation of the standard errors of estimates and spurious significant results. Statistical methods are described separately for the continuous variables (knowledge, attitudes, and beliefs) and discrete variables (smoking behaviour).

Gender, mother's smoking status, father's smoking status, and father's occupation at baseline were considered potential confounding variables, particularly as differences in rates of smoking and levels of knowledge were evident among study groups at baseline. Parental smoking was dichotomised (regular or occasional smoker $v$ non-smoker, former smoker or not known), and father's occupation was categorised into four groups: manual, non-manual, unemployed, and not known (this last category made up $21 \%$ (943) of the 4538 responses).

The continuous variables knowledge, attitudes, and beliefs about smoking were assessed on five scales. The knowledge score was based on 12 items. For each item a correct response was given a score of 1 and an incorrect, not sure, or missing response was scored as 0 . For students with two or fewer missing responses the values on the individual items were summed to yield an overall score between 0 and 12 . The remaining students were excluded from the analysis. A three point scale was used for each of the 12 self esteem items. A response indicating high self esteem was coded as 2 , low self esteem 0 , and not sure or missing 1 . For students with no more than two missing responses 
the individual values were summed to give a score between 0 and 24 .

The remaining variables were measured on a five point Likert scale. Scores were obtained by averaging the responses. If there were too many missing responses no score was given for that student. For perceived health values there were five items; no more than two responses were allowed to be missing. External locus of control was measured on four items, no more than one of which was allowed to be missing. Internal locus of control had two items and no missing items were allowed. The proportion of missing values on the five scales ranged from $0 \cdot 2 \%$ to $3 \cdot 1 \%$ and was generally less than $2 \%$.

For each scale the baseline score in 1988, changes from baseline to first follow up (1989), and changes from baseline at second follow up (1990) were compared among intervention groups. Mixed model analysis of variance was used to test for the effects of intervention. School was fitted as a random effect nested within groups. The two projects were fitted as fixed effects. Where there was no significant interaction (effect modification) between the projects, the separate effects of each project (main effects) were assessed. Each model also included the potential confounders discussed above. The maximum likelihood method was used to fit the models by the BMDP3V computer program. ${ }^{26}$ The likelihood ratio test ( $\chi^{2}$ statistic) was used to test hypotheses.

Students were asked to indicate which of six statements relating to smoking behaviour best described their own behaviour. The responses were later grouped into three categories: (a) never smoker- "I have never smoked a cigarette, not even a puff"; $(b)$ tried but stopped-"I have only ever tried smoking once or twice but I don't smoke now," or "I used to smoke sometimes but I don't smoke now"; (c) current

TABLE I-Sociodemographic data at baseline on children in schools randomised to use no intervention, family smoking education project (FSE), smoking and me project (SAM), or both projects. Figures are numbers (percentages)

\begin{tabular}{|c|c|c|c|c|c|}
\hline & $\begin{array}{c}\text { Total } \\
(n=4538)\end{array}$ & $\begin{array}{c}\text { Control } \\
(n=1229)\end{array}$ & $\begin{array}{c}\text { FSE } \\
(\mathrm{n}=1127)\end{array}$ & $\underset{(n=1021)}{S A M}$ & $\begin{array}{r}\text { FSE/SAM } \\
(n=1161)\end{array}$ \\
\hline \multicolumn{6}{|l|}{ Age (years): } \\
\hline 11 & $2295(50 \cdot 6)$ & $637(51 \cdot 8)$ & $563(50 \cdot 0)$ & $511(50 \cdot 0)$ & $584(50 \cdot 3)$ \\
\hline 12 & $2243(49 \cdot 4)$ & $592(48 \cdot 2)$ & $564(50 \cdot 0)$ & $510(50 \cdot 0)$ & $577(49 \cdot 7)$ \\
\hline \multicolumn{6}{|l|}{ Sex: } \\
\hline Girl & $2188(48 \cdot 2)$ & $586(47 \cdot 7)$ & $544(48 \cdot 3)$ & $482(47 \cdot 2)$ & $576(49 \cdot 7)$ \\
\hline Boy & $2347(51.8)$ & $643(52 \cdot 3)$ & $582(51 \cdot 7)$ & $539(52 \cdot 8)$ & $583(50 \cdot 3)$ \\
\hline \multicolumn{6}{|l|}{ Father smokes: } \\
\hline Yes* & $1968(43 \cdot 4)$ & $540(43 \cdot 9)$ & $461(40 \cdot 9)$ & $450(44 \cdot 1)$ & $517(44 \cdot 5)$ \\
\hline No† & $2570(56 \cdot 6)$ & $689(56 \cdot 1)$ & $666(59 \cdot 1)$ & $571(55.9)$ & $644(55 \cdot 5)$ \\
\hline \multicolumn{6}{|l|}{ Mother smokes: } \\
\hline Yes` & $1551(34 \cdot 2)$ & $394(32 \cdot 1)$ & $380(33 \cdot 7)$ & $367(35.9)$ & $410(35 \cdot 3)$ \\
\hline Not & $2987(65 \cdot 8)$ & $835(67 \cdot 9)$ & $747(66 \cdot 3)$ & $654(64 \cdot 1)$ & $751(64 \cdot 7)$ \\
\hline \multicolumn{6}{|l|}{ Father's job: } \\
\hline Non-manual & $1369(30 \cdot 2)$ & $370(30 \cdot 1)$ & $323(28 \cdot 7)$ & $292(28 \cdot 6)$ & $384(33 \cdot 1)$ \\
\hline Manual & $1865(41 \cdot 1)$ & $499(40 \cdot 6)$ & $482(42 \cdot 8)$ & $418(40.9)$ & $466(40 \cdot 1)$ \\
\hline Unemployed & $361(8 \cdot 0)$ & $101(8 \cdot 2)$ & $90(8 \cdot 0)$ & $84(8 \cdot 2)$ & $86(7 \cdot 4)$ \\
\hline Not known & $943(20 \cdot 8)$ & $259(21 \cdot 1)$ & $232(20 \cdot 6)$ & $227(22 \cdot 2)$ & $225(19 \cdot 4)$ \\
\hline
\end{tabular}

TABLE II-Number (percentage) of children who had never smoked, had tried smoking, or smoked according to intervention project

\begin{tabular}{lccccc}
\hline & Total & Control & FSE & SAM & FSE/SAM \\
\hline Never smoker: & & & & & \\
$\quad 1988$ & $3455(78 \cdot 7)$ & $951(79 \cdot 6)$ & $848(77 \cdot 6)$ & $732(74 \cdot 0)$ & $924(83 \cdot 0)$ \\
1989 & $2693(70 \cdot 2)$ & $744(71 \cdot 8)$ & $639(68 \cdot 1)$ & $577(65 \cdot 6)$ & $733(74 \cdot 6)$ \\
$\quad 1990$ & $2180(58 \cdot 4)$ & $626(62 \cdot 0)$ & $486(53 \cdot 8)$ & $469(55 \cdot 7)$ & $599(61 \cdot 1)$ \\
Tried smoking: & & & & & \\
$\quad 1988$ & $826(18 \cdot 8)$ & $218(18 \cdot 2)$ & $225(20 \cdot 6)$ & $213(21 \cdot 5)$ & $170(15 \cdot 3)$ \\
1989 & $940(24 \cdot 5)$ & $249(24 \cdot 0)$ & $244(26 \cdot 0)$ & $238(27 \cdot 0)$ & $209(21 \cdot 3)$ \\
$\quad 1990$ & $112(29 \cdot 8)$ & $270(26 \cdot 7)$ & $288(31 \cdot 9)$ & $272(32 \cdot 3)$ & $282(28 \cdot 8)$ \\
Current smoker: & & & & & \\
$\quad 1988$ & $109(2 \cdot 5)$ & $26(2 \cdot 2)$ & $20(1 \cdot 8)$ & $44(4 \cdot 4)$ & $19(1 \cdot 7)$ \\
1989 & $203(5 \cdot 3)$ & $43(4 \cdot 2)$ & $55(5 \cdot 9)$ & $65(7 \cdot 4)$ & $40(4 \cdot 1)$ \\
1990 & $444(11 \cdot 9)$ & $114(11 \cdot 3)$ & $130(14 \cdot 4)$ & $101(12 \cdot 0)$ & $99(10 \cdot 1)$ \\
Total No of children ${ }^{\star}$ & & & & & \\
1988 & 4390 & 1195 & 1093 & 989 & 1113 \\
1989 & 3836 & 1036 & $938 \cdot$ & 880 & 982 \\
1990 & 3736 & 1010 & 904 & 842 & 980 \\
\hline
\end{tabular}

FSE=family smoking and education project; $S A M=$ smoking and me project.

*Pupils for whom smoking status was known.
smoker-“I smoke sometimes but I don't smoke as much as one cigarette a week" or "I usually smoke between one and six cigarettes a week," or "I usually smoke more than six cigarettes a week."

Since one main aim of the interventions was to delay the onset of smoking, never smoking was considered an appropriate primary indicator given the age of the pupils at baseline (relatively few were current smokers or had previously experimented with smoking). Nonsmoking (never smoking combined with tried but stopped) was used as a second end point.

The proportion of students remaining never smokers at first follow up and at second follow up was assessed. Rates of non-smoking in never smokers were also assessed at each follow up. Analyses comparing rates of non-smoking among study groups at each follow up were repeated for non-smokers at baseline rather than never smokers. Overall findings of these analyses are given to assess the sensitivity of the main results to the choice of target group.

The $\chi^{2}$ test was used to test for overall differences in proportions across the four intervention groups. To adjust for the effect of clustering, $X_{a d j}^{2}$ was calculated by dividing the resulting $\chi^{2}$ statistic by $\left(\sum_{i=1}^{39} m_{i}\left(1+\rho\left(m_{i}-1\right)\right)\right) / \varepsilon_{l=i}^{39} m_{i}$ where $m_{i}$ represents the number of students in the $i$ th cluster (school) and $\rho$ represents the intracluster correlation. ${ }^{27}$ For each outcome the average interclass correlation across the four study groups was used as the estimate for $\rho .^{28}$ This method of analysis does not take into account the factorial design.

Logistic regression was used to model change in smoking behaviour at each follow up taking into account the factorial design, the clustering, and the potential confounders. For each analysis, a series of models was fitted with the statistical package GLIM. ${ }^{29}$ When variables are added to a model the change in deviance follows an approximate $\chi^{2}$ distribution with degrees of freedom ( $\mathrm{df}$ ) equal to the number of additional parameters fitted. By fitting appropriate models, after adjusting for potential confounders, the analogue of a mixed model analysis of variance table was constructed. Tests of significance for intervention effects were then carried out by taking the ratio $\left(\chi^{2} / \mathrm{df}\right.$ for the intervention effect $) /\left(\chi^{2} / \mathrm{df}\right.$ for the interaction between school and interventions) to yield an approximate $F$ statistic. ${ }^{30}$

\section{Results}

In 1988, 5078 pupils aged 11 and 12 and in their first year of secondary school were eligible for inclusion in the study. Of these, $4562(90 \%)$ completed questionnaires, 4538 of which were valid for use in the analysis. The percentage valid for use in the four groups varied between $92 \%$ and $86 \%$. No pupils refused to participate in the study, and as pupils were not warned about the administration of the survey we assumed that those registered pupils who did not complete the survey were either absent or had left the school.

Table I gives a summary of the sociodemographic characteristics and parental smoking of the four groups. Overall, the groups were similar in age, sex, father's and mother's smoking status, and father's occupation. There was a significant difference $\left(\chi_{a d j}^{2}=9 \cdot 5, \mathrm{df}=3\right.$; $\mathrm{p}=0.02$ ) in the rates of reported never smoking between the groups (table II). The FSE/SAM group had the highest proportion of never smokers $(83 \%$, $924 / 1113)$, and the SAM group the lowest $(74 \%$, $732 / 989)$; the 148 pupils for whom smoking status was not known were excluded from the data. A logistic model indicated that this difference was not explained by the small discrepancies in the sociodemographic characteristics $\left(F_{3,35}=3 \cdot 2, \mathrm{p}<0 \cdot 05\right)$. Similarly, there 
TABLE III-Mean (SD) scores for knowledge, attitude, and belief scales in 1988 and changes from baseline score at first and second follow up according to intervention group

\begin{tabular}{|c|c|c|c|c|c|c|}
\hline & $\begin{array}{l}\text { No of } \\
\text { pupils }\end{array}$ & Total & Control & FSE & SAM & FSE/SAM \\
\hline \multicolumn{7}{|c|}{ Knowledge $(\max 12):$} \\
\hline 1988 & 4527 & $5 \cdot 40(2 \cdot 0)$ & $5 \cdot 18(2 \cdot 0)$ & $5.57(1.9)$ & $5.38(1.9)$ & $5.47(2 \cdot 0)$ \\
\hline 1989 & 3911 & $0.96(2 \cdot 1)$ & $0.78(2.0)$ & $0.95(2 \cdot 1)$ & $0.82(2.0)$ & $1 \cdot 28(2 \cdot 1)$ \\
\hline 1990 & 3776 & $1.06(2 \cdot 2)$ & $1.04(2.2)$ & $1.09(2.2)$ & $0.91(2.2)$ & $1 \cdot 18(2 \cdot 1)$ \\
\hline \multicolumn{7}{|c|}{ Self esteem $(\max 24)$ : } \\
\hline 1988 & 4509 & $15 \cdot 47(5 \cdot 0)$ & $15 \cdot 48(4 \cdot 8)$ & $15 \cdot 38(4 \cdot 9)$ & $15 \cdot 48(5 \cdot 3)$ & $15 \cdot 52(5 \cdot 1)$ \\
\hline 1989 & 3891 & $1.39(4.5)$ & $1.51(4.4)$ & $1.37(4 \cdot 4)$ & $1 \cdot 12(4 \cdot 8)$ & $1.51(4.6)$ \\
\hline 1990 & 3757 & $2 \cdot 08(4 \cdot 8)$ & $2 \cdot 02(4 \cdot 7)$ & $2 \cdot 20(4 \cdot 7)$ & $1.95(4.9)$ & $2 \cdot 15(4 \cdot 9)$ \\
\hline \multicolumn{7}{|c|}{ Health values $(\max 5)$ : } \\
\hline 1988 & 4501 & $4.24(0.6)$ & $4 \cdot 19(0 \cdot 6)$ & $4.27(0.6)$ & $4 \cdot 26(0 \cdot 6)$ & $4 \cdot 24(0 \cdot 6)$ \\
\hline 1989 & 3875 & $0.08(0.6)$ & $0.08(0.6)$ & $0.06(0.7)$ & $0.08(0.6)$ & $0.09(0.7)$ \\
\hline 1990 & 3748 & $0.03(0.7)$ & $0.03(0.7)$ & $0.01(0.7)$ & $0.06(0.7)$ & $0.02(0 \cdot 7)$ \\
\hline \multicolumn{7}{|c|}{ External locus of control $(\max 5)$ : } \\
\hline 1988 & 4475 & $3.51(0.7)$ & $3.52(0.7)$ & $3.50(0 \cdot 8)$ & $3 \cdot 54(0 \cdot 7)$ & $3.49(0 \cdot 7)$ \\
\hline 1989 & 3838 & $0.30(0.7)$ & $0.31(0.7)$ & $0.25(0.7)$ & $0.25(0.7)$ & $0.38(0.7)$ \\
\hline 1990 & 3718 & $0.45(0.7)$ & $0.45(0.7)$ & $0.42(0.8)$ & $0.41(0.7)$ & $0.52(0.8)$ \\
\hline \multicolumn{7}{|c|}{ Internal locus of control $(\max 5)$ : } \\
\hline 1988 & 4456 & $3.91(0.6)$ & $3.89(0.6)$ & $3.95(0.6)$ & $3.90(0.6)$ & $3.91(0.6)$ \\
\hline 1989 & 3806 & $0.08(0.7)$ & $0.09(0.7)$ & $0.04(0.7)$ & $0.09(0.7)$ & $0 \cdot 10(0 \cdot 8)$ \\
\hline 1990 & 3677 & $0.08(0.7)$ & $0.10(0.7)$ & $0.03(0.7)$ & $0.07(0.7)$ & $0 \cdot 10(0 \cdot 7)$ \\
\hline
\end{tabular}

FSE=family smoking education project; $S A M=$ smoking and me project.

^Excluding pupils with missing values.

was a difference between groups in the rates of reported non-smoking $\left(\chi_{a d j}^{2}=9 \cdot 2, \mathrm{df}=3 ; \mathrm{p}=0.03\right)$; this difference was no longer significant after potential confounders were adjusted for $\left(F_{3,35}=2 \cdot 5\right)$.

Table III gives scores at baseline for knowledge, self esteem, health values, internal locus of control, and external locus of control. After adjustment for sociodemographic variables the mean knowledge score in the FSE groups (FSE and FSE/SAM) was found to be significantly higher than that in the control and SAM groups $\left(\chi^{2}=5 \cdot 7, \mathrm{df}=1 ; \mathrm{p}=0 \cdot 02\right)$. No significant differences were found on the other four scales. Baseline differences were allowed for in the follow up analyses by examining changes from baseline.

In $1989,3930(87 \%)$ of the 4538 pupils who completed the survey at baseline were surveyed again. The follow up rates for the groups were control group $86 \%$ (1056/1229), FSE group 85\% (960/1127), SAM group $88 \%(895 / 1021)$, and FSE/SAM group $88 \%$ $(1019 / 1161)$. In $1990,3786(83 \%)$ of the 1988 group were followed up. Follow up rates were control group 83\% (1024/1229), FSE group 81\% (916/1127), SAM group $84 \%(854 / 1021)$ and FSE/SAM group $85 \%$ (992/1161). Overall 94\% (4262) of the original group participated in at least one follow up study (either 1989 or 1990), and $76 \%$ (3454) were followed up in both 1989 and 1990. These figures suggest that loss at follow up was largely due to absenteeism on the day of the survey rather than migration. Pupils were significantly less likely to have participated in the follow up studies if at baseline they had reported being smokers or having previously smoked or tried cigarettes, if their father or mother was a smoker, or if their father was unemployed or a manual worker. These findings were consistent across all four groups.

CHANGES IN SMOKING BEHAVIOUR

Table II gives the prevalence of smoking at follow up. Table IV gives rates of self reported smoking in
1989 and 1990 among pupils who were never smokers in 1988. A total of 3037 of the never smokers at baseline participated in the 1989 survey. Rates of remaining a never smoker in 1989 for the 2981 (98\%) for whom smoking status was known at this first follow up were $85 \%$ in the control group, $82 \%$ in the FSE group, $81 \%$ in the SAM group, and $84 \%$ in the FSE/SAM group. No significant differences in the proportions of students remaining never smokers or non-smokers were found. Similarly, no significant differences were found in the proportions who remained non-smokers among groups in 1989.

A total of 2958 never smokers in 1988 were surveyed in $1990,2924(99 \%)$ of whom gave a valid response for smoking status. Rates of remaining a never smoker for this group were: $74 \%$ in the control group, $65 \%$ in the FSE group, $70 \%$ in the SAM group, and $69 \%$ in the FSE/SAM group. The $\chi^{2}$ analysis showed no significant differences in smoking status between the four groups at second follow up $\left(\chi_{a d j}^{2}=6 \cdot 1, \mathrm{df}=3\right.$; $\mathrm{p}=0 \cdot 1)$. The logistic model, taking into account the factorial design and potential confounders, identified a significant difference in the odds of remaining a never smoker between the groups using the family and smoking education project and those not using it $\left(F_{1,35}=4 \cdot 2, \mathrm{p}<0.05\right)$, the groups using the project being less likely to remain never smokers. Comparing the proportion of never smokers in the groups using the family and smoking project and those not using it by $\chi^{2}$ analysis gave a result consistent with the results of the model $\left(\chi_{a d j}^{2}=3 \cdot 7, d f=1 ; \mathrm{p}=0 \cdot 05\right)$. No significant differences were found in the proportions remaining non-smokers. Similarly, no differences were found between intervention groups in the proportions of nonsmokers at baseline who remained non-smokers in 1990 by either method of analysis.

\section{CHANGES IN KNOWLEDGE, ATTITUDES, AND BELIEFS}

All four groups showed an overall increase in scores for knowledge, attitudes, and beliefs between 1988 and 1989 (table III). The mean scores at baseline for the subgroup of students who were followed up were the same as for those not followed up. Mixed model analysis of variance showed that the mean increase in knowledge was significantly higher in the FSE groups (FSE and FSE/SAM, $\chi^{2}=8 \cdot 3, \mathrm{df}=1 ; \mathrm{p}=0 \cdot 004$ ). For external locus of control a lower increase in score was seen in the FSE and SAM groups than in the control group, but the increase in the FSE/SAM group was higher than that in the control group. This is reflected in the significant interaction between FSE and SAM found for the change in external locus of control $\left(x^{2}=8 \cdot 0, \mathrm{df}=1 ; \mathrm{p}=0 \cdot 005\right)$. No significant intervention effects were found for the other scales. Very little change in the score for health values was observed in any group.

The change from baseline in knowledge, attitude, and belief at the 1990 follow up are also given in table III. A significant interaction was found between FSE and SAM in the model for change in external locus of control $\left(\chi^{2}=4.4, \mathrm{df}=1 ; \mathrm{p}=0.04\right)$, the pattern of

TABLE IV-Smoking behaviour at follow up among never smokers in 1988 according to intervention group

\begin{tabular}{|c|c|c|c|c|c|c|}
\hline & Total & Control & FSE & SAM & FSE/SAM & \\
\hline \multicolumn{7}{|l|}{ 1989: } \\
\hline No of never smokers in 1988 followed up & 2981 & 823 & 721 & 643 & 794 & \\
\hline No $(\%)$ of never smokers & $2482(83 \cdot 3)$ & $697(84 \cdot 7)$ & $594(82 \cdot 4)$ & $523(81 \cdot 3)$ & $668(84 \cdot 1)$ & $\chi_{a d d}^{2}=1 \cdot 4, \mathrm{df}=3 ; \mathrm{p}=0 \cdot 7$ \\
\hline No $(\%)$ who tried smoking & $424(14 \cdot 2)$ & $114(13.9)$ & $105(14 \cdot 6)$ & $98(15 \cdot 2)$ & $107(13.5)$ & \\
\hline No $(\%)$ of current smokers & $75(2.5)$ & $12(1.5)$ & $22(3 \cdot 0)$ & $22(3 \cdot 4)$ & $19(2 \cdot 4)$ & $\chi_{a d}^{2}=4 \cdot 7, \mathrm{df}=3 ; \mathrm{p}=0 \cdot 2^{\star}$ \\
\hline \multicolumn{7}{|l|}{ 1990: } \\
\hline No of never smokers in 1988 followed up & 2924 & 804 & 704 & 625 & 791 & \\
\hline No $(\%)$ of never smokers & $2038(69 \cdot 7)$ & $594(73.9)$ & $455(64 \cdot 6)$ & $440(70 \cdot 4)$ & $549(69 \cdot 4)$ & $\chi_{d d}^{2}=6 \cdot 1, d f=3 ; \mathrm{p}=0 \cdot 1$ \\
\hline No $(\%)$ who tried smoking & $664(22 \cdot 7)$ & $159(19 \cdot 8)$ & $173(24 \cdot 6)$ & $148(23.7)$ & $184(23 \cdot 3)$ & \\
\hline No (\%) of current smokers & $222(7 \cdot 6)$ & $51(6 \cdot 3)$ & $76(10 \cdot 8)$ & $37(5.9)$ & $58(7 \cdot 3)$ & $\chi_{a d j}^{2}=6 \cdot 2, \mathrm{df}=3 ; \mathrm{p}=0 \cdot 1^{\star}$ \\
\hline
\end{tabular}

FSE=family smoking education project; $\mathrm{SAM}=$ smoking and me project.

FSE=family smoking education project; $S A M=s m o k i n g$ and me project.
${ }^{*}$ Comparisons of current smoking are equivalent to comparisons of non-smoking. $\chi_{a d j}^{2}$ is the $\chi^{2}$ statistic adjusted for clustering. 
change being similar to that seen in 1989 . No other significant effects were found.

Further analysis showed no differences in results between schools in which the projects were taught for only the minimum time compared with those that taught it for longer. Examination of records available on smoking related activity in the control schools indicated that pupils in half of the schools had been exposed to some incidental and unplanned smoking education through events such as No Smoking Day or through associated teaching in home economics or biology. In none of these cases could the exposure be classified as substantial enough to call into question the validity of the control schools.

\section{Discussion}

Our results are very disappointing. They contrast with those from many studies in the early 1980s which showed a clear impact on teenage smoking behaviour ${ }^{31-33}$ but are consistent with findings from other recent and comparable studies. ${ }^{34}{ }^{35}$ Some small differences in the achievement of educational objectives were observed, but our results suggest that two of the best school smoking education projects in Britain have not achieved better results than non-specific population wide approaches.

The results are difficult to explain. This study deliberately examined the impact of the projects under normal classroom conditions. Previous success with the original Minnesota smoking prevention programme may have arisen from the experimental classroom conditions under which it was taught. Results available from two recent trials of programmes based on the original Minnesota model also show disappointing findings in their impact on smoking behaviour. In both cases these programmes were taught under real life conditions, by ordinary classroom teachers. ${ }^{36} 37$

No corresponding studies for the family smoking education project have been published and there may be other explanations for the poor results. The Norwegian project was directed at school pupils aged 13-14 years, among whom the prevalence of smoking was high. The behavioural objective in Norway was to reduce established prevalence of smoking. In the British version, which was directed at a younger age group (10-12 years) with a lower smoking prevalence, the objective was to minimise or delay uptake. Furthermore, the trial in Norway was conducted during a period of consistent decrease in the prevalence of smoking among young people in the country and while a comprehensive tobacco control programme was being introduced. This included controls on the price, availability, and promotion of tobacco products. No similar conditions existed in Britain at the time of this study.

\section{EVALUATION OF PROGRAMMES}

Our results indicate the need for a closer examination of the intended behavioural outcomes in school based programmes. Both projects went through limited field testing to examine teacher and pupil acceptability before widespread dissemination. Given that the problem of teenage smoking needed to be tackled with some urgency at that time (and still does), such a course of action was understandable. However, in the future such rapid widespread dissemination of promising innovations will need to be accompanied by enhanced efforts to monitor intended behavioural outcomes and by testing of school projects in real life settings.

Our results also point to a more fundamental need for British based research into the most effective ways of influencing rates of smoking among young people through schools. For example, since the original design of both projects the age of onset of smoking has fallen. Specific health education programmes at ages 10-12 (for the family smoking education project) or 12-13 (for the smoking and me project) may well be too late or offer no additional benefit to more general interventions at that age. Strong attitudes may have formed by then and teaching of avoidance skills may be too late to immunise children effectively against the pressures to smoke. Education programmes at earlier ages in primary schools might be more successful. Other countries are also facing these problems. Disappointing findings have recently been reported from long term follow up studies of school based interventions in North America. Reviews of school smoking prevention programmes have shown continuing success in delaying onset of smoking, but school health education alone may not be sufficient to compensate for other substantial influences on teenage smoking behaviour. ${ }^{38}{ }^{39}$ Other influences include the supply and availability of cigarettes to young people, their price and promotion, and the example of adults, especially those who may be role models for young people. ${ }^{40-42}$

Cigarettes are still relatively easy to obtain by young people, and current arrangements for enforcing legislation to restrict sales are largely ineffective. In additon, young people's purchasing patterns can be influenced by the advertising and tobacco sponsorship of sports. ${ }^{434}$ Restrictions on advertising and sports sponsorship can have an immediate impact on rates of teenage smoking. ${ }^{45-46}$ Young people are also more likely to be sensitive to the high price of tobacco products. ${ }^{47}$

A model for achieving a smoke free generation in Europe was proposed at the first European conference on tobacco in 1988 and was supported by the World Health Organisation and British Medical Association. ${ }^{48}$ Since then a report of the Royal College of Physicians has also emphasised the need for a comprehensive approach to the problem which takes account of the wide range of factors influencing both the supply of tobacco products and demand for them by young people. ${ }^{40}$ Such a strategy recognises a clear role for school health education but emphasises that achieving an impact on the minority of young people who choose to smoke will require more substantial and comprehensive interventions.

We thank Michael Booth and Zoanne Nugent for help in assembling the database, Ruth Newman for conducting the fieldwork, Gareth Morgan and Elwyn Williams for fieldwork support, Leif Aaro and David Murray for comments on differences in results with the original programmes, and Donald Reid, Jeanie McKenzie, and Graham Hathaway for comments on the manuscript.

1 Bynner JM. The young smoker: smoking among schoolboys. London: HMSO, 1969

2 Rawbone RG, Guz A. Cigarette smoking among secondary schoolchildren 1975-9. Arch Dis Child 1982;57:352-8.

3 Murray M, Swan AV, Bewley BR, Johnson MRD. The development of smoking during adolescence-the MRC Derbyshire smoking study. Int f Epidemiol 1983;12:3-9.

4 Bewley BR, Johnson MRD, Bland JM, Murray M. Trends in children's smoking. Community Med 1980;2:186-9.

Dobbs J, Marsh A. Smoking among secondary schoolchildren. London: HMSO, 1983.

6 Dobbs J. Marsh A. Smoking among secondary schoolchildren in 1984. London: HMSO, 1985.

7 Goddard E, Ikin C. Smoking among secondary schoolchildren in 1986. London: HMSO, 1987.

8 Goddard E. Smoking among secondary schoolchildren in England in 1988. London: HMSO, 1989.

9 Lader D, Matheson J. Smoking among secondary schoolchildren in 1990. London: HMSO, 1991.

10 Thompson EL. Smoking education programmes 1960-76. Am f Public Health 1978;68:250-7.

11 Evans RI, Rozelle RM, Maxwell SE, Raines BE, Dill CA, Guthrie TJ, et al. Social modelling films to deter smoking in adolescents: results of a three year field investigation. F Appl Psychol 1981;66:399-414.

12 Arkin RM, Roemhild HF, Johnson CA, Leupker RV, Murray DM. The Minnesota smoking prevention program. I Sch Health 1981;11:611-6.

13 Botvin GJ, Eng A, Williams P. Preventing the onset of smoking through life Botvin G], Eng A, Williams P. Preventing
skills training. Prev Med 1980;9:135-43. 
14 Aaro LE, Bruland E, Hauknes A, Lochsen PM. Smoking among Norwegian schoolchildren 1975-1980: the effect of antismoking campaigns. Scand $\mathcal{F}$ Psychology 1982;24:277-83.

15 Health Education Authority. The family smoking education project (parents leaflet, pupils' leaflet, and teachers' booklet). London: Health Education Authority, 1991

16 Murray M, McReynolds F, McGrath A. An evaluation of different versions of the family smoking education program. Coleraine: Centre for Applied Health Studies, 1988.

7 Health Education Authority. Smoking and me (smoking education for teenagers project teachers guide). London: Health Education Authority, 1991.

18 Blackwell SE. Assessing the effectiveness of "smoking and me." Aylesbury: Aylesbury Vale Health Authority, 1988

19 Nutbeam D. Smoking and schoolchildren in Wales: a new programme. Educ Health 1988;6:52-7.

20 Lawrence D. The development of a self esteem questionnaire. $B r \mathcal{I} E d u c$ Psychol 1981;51:245-51.

21 Aaro LE, Wold B. Health behaviour in schoolchildren: a WHO cross national survey. Research protocol. Copenhagen: WHO Regional Office for Europe; survey. Research protocol. Copenhagen: WHO Regional Office

$22 \mathrm{McKennel}$ AC. Bias in the reported incidence of smoking amongst schoolchildren. In I Epidemiol 1980;9:167-77.

23 Pechacek T, Fox B, Murray D, Leupker R. Review of techniques for measurement of smoking behaviour. In: Matarazzo JD, Herd J, Miller N Weiss S, eds. Behavioural health: a handbook of health enhancement and disease prevention. New York: Wiley-Interscience, 1984:729-54.

24 Newman R, Nutbeam D. Teachers' views of the family smoking education project. Health Educ $\mathcal{F}$ 1989;48:9-13.

25 Newman R, Smith C, Nutbeam D. Teachers' views of the "smoking and me" project. Health Educ f 1991;50:107-10.

26 BMDP statistical software manual. Vol 2. Los Angeles: BMDP Statistical Software, 1990.

27 Brier SS. Analysis of contingency tables under cluster sampling. Biometrika 1990;67:591-6.

28 Donald A, Donner A. Adjustments to the Mantel-Haenszel chi square statistics and odds ratio variance estimator when the data are clustered. Stat Med 1987;6:491-9.

29 Baker RJ. GLIM 3.77 reference guide. Oxford: Numerical Algorithms Group, 1987

30 Aitken M, Anderson D, Francis B, Hinds J. Statistical modelling in GLIM. Oxford: Clarendon Press, 1989

31 Vartianinen E, Pallonen U, McAlister A, Koskela K, Puska P. Effect of two years' educational intervention in adolescent smoking (the North Karelia youth project). Bull World Health Organ 1983;61:529-32.

32 Tell GS, Klepp KI, Vellar OD, McAlister A. Preventing the onset of smoking in N No-75.

Ross JG. Effectiveness of a health education curriculum for secondary schoo students-United States, 1986-89. MMWR 1991;40:113-6.

34 Murray DM, Pirie P, Leupker RV, Pallonen U. Five and six year follow-up results from four seventh grade smoking prevention strategies. I Behav Med

35 Flay BR, Koepke D, Thomas SJ, Santi S, Best JA, Brown KS. Six year followup of the first Waterloo smoking prevention trial. Am $f$ Public Health 1989;79:1371-6

36 Kishchuk N, O'Loughlin J, Paradis S, Masson P, Sacks-Silver G. Illuminating negative results in evaluation of smoking prevention programs. $f$ Sch Health 1990;60:448-51.

37 Murray DM. The Minnesota-Wisconsin adolescent tobacco use research project: final report. Minneapolis: Division of Epidemiology, School of Public Health, University of Minnesota, 1992.

38 Glynn TJ. Essential elements of school-based smoking prevention programs. I Sch Health 1989;59:181-8.

39 Charlton A, Melia P, Moyer C. A manual on tobacco and young people for the industrialised world. Geneva: IUCC, 1990.

40 Royal College of Physicians. Smoking and the young. Repon of a working party, Royal College of Physicians. London: RCP, 1992.

41 United States Department of Health and Human Services. Reducing the health consequences of smoking: 25 years of progress. A repon of the surgeon-general. Washington, DC: Government Printing Office, 1989. (DHHS Pub No (CDC) 89-8411.)

2 Males $M$. Youth behaviour: subcultural effect or mirror of adult behaviour? I Sch Health 1990;60:505-8.

43 Potts $\mathrm{H}$, Gillies P, Herbert $\mathrm{M}$. Adolescent smoking and opinion of cigarette advertisements. Health Educ Res 1986;1:195-201.

44 Aitken P, Leather D, Squair S. Children's awareness of brand sponsorship of sports and games in the UK. Health Educ Res 1986;1:203-11.

45 Chapman S, White P. Pushing smoke: tobacco advertising and promotion. Copenhagen: World Health Organisation, British Medical Association, 1989:39.

46 New Zealand Toxic Substances Board. Health or tobacco-an end to tobacco advertising and promotion. Wellington, New Zealand: Department of Health, 1989.

47 Townsend J. Tobacco price and the smoking epidemic. Copenhagen: World Health Organisation, British Medical Association, 1989:52-3.

48 Nutbeam D. Planning for a smoke-free generation. Copenhagen: World Health Organisation, British Medical Association, 1989.

(Accepted 6 October 1992)

\section{Fatal hepatic decompensation associated with interferon alfa}

Department of Internal

Medicine II, University

Hospital Dijkzigt, 3015 GD

Rotterdam, The

Netherlands

H L A Janssen, research

fellow

J T Brouwer,

hepatogastroenterologist

\section{Department of}

Hepatogastroenterology,

University Hospital,

Leuven, Belgium

F Nevens,

hepatogastroenterologist

Liver Unit, Hospital Clinic

I Provencial, Barcelona,

Spain

J M Sanchez-Tapias,

hepatogastroenterologist

Divisione di Medicina

Interna, University of

Palermo, Italy

A Craxi, professor of

hepatology

Academic Department of Medicine, Hippokration

General Hospital, Athens,

Greece

S Hadziyannis, professor of

hepatology

Correspondence to:

Dr Janssen.

BMF 1993;306:107-8
H L A Janssen, J T Brouwer, F Nevens,

J M Sanchez-Tapias, A Craxi, S Hadziyannis,

European concerted action on viral hepatitis

(Eurohep)

Interferon alfa is the most promising treatment for chronic viral hepatitis, suppressing viral replication in about $30 \%$ of patients with chronic hepatitis B or C. ${ }^{12}$ In patients with cirrhosis interferon alfa may improve the outcome of the disease and obviate the need for liver transplantation. ${ }^{3}$ Inhibition of viral replication in chronic hepatitis $\mathrm{B}$ is usually accompanied by a transient rise in the activities of aminotransferases. This inflammatory exacerbation may cause hepatic decompensation in cirrhotic patients. We report on patients with chronic viral hepatitis who died of hepatic decompensation during or shortly after interferon alfa treatment.

\section{Case reports}

After a patient with chronic hepatitis B in our institute exhibited a flare of hepatitis during interferon alfa treatment and died we studied the frequency and clinical aspects of fatal hepatic decompensation related to interferon alfa treatment. We sent a questionnaire to 19 European centres with considerable experience of interferon alfa treatment for viral hepatitis. Sixteen hospitals from nine countries responded. These centres had treated 2490 patients with chronic viral hepatitis with interferon alfa. We studied cases in which the patient had a fatal aggravation of liver disease during or less than two months after interferon alfa treatment. Eight cases from five hospitals were reported; the table gives details of these cases plus our case.

Histological examination before treatment showed that all the patients had chronic active hepatitis with cirrhosis. Four had no signs of hepatic decompensation (ascites, jaundice, encephalopathy, or variceal bleeding) before treatment. Clinical deterioration occurred in the first three months of treatment in seven cases. In cases 7 and 8 the scheduled course of treatment was completed with clearance of viral DNA, but liver failure developed two and eight weeks later. Five patients' aminotransferase activities more than doubled during treatment. No apparent reason for the liver failure other than interferon alfa treatment could be detected in any of the patients.

\section{Comment}

Although these cases were selected from a large number in which interferon alfa was given, they suggest that the drug can dangerously aggravate liver disease and that caution is needed in treating cirrhotic patients. A relation between liver failure and interferon alfa seems probable in the patients who did not have hepatic decompensation before treatment. The deaths of patients who showed signs of decompensated liver disease before treatment might have been due to spontaneous progression of the disease and cannot be linked unequivocally to the interferon treatment.

Most of the patients developed ascites, jaundice, and encephalopathy that progressed even after interferon alfa was stopped. Since five of the patients received $<10 \mathrm{MU}$ interferon/week fatal hepatic decompensation was not restricted to high dosages of the drug. Relatively late discontinuation of treatment could be a reason for the unfavourable outcome in some cases.

There are several possible explanations for a link between interferon alfa and fatal hepatic injury. Interferon alfa enhances lysis mediated by the immune system of hepatocytes infected with hepatitis B virus, 